\title{
LA AUDITORÍA FORENSE: UN MECANISMO PARA DETECTAR EL FRAUDE DE ESTADOS FINANCIEROS EN COLOMBIA ${ }^{1}$
}

\author{
Yaneth Zambrano Vargas²
}

Para citar este artículo: Zambrano, Y. (2015). La auditoría forense: un mecanismo para detectar el fraude de estados financieros en Colombia. Inquietud Empresarial. Vol. XV (2), 13-36.

Fecha de recepción: 2 de junio de 2015 Fecha de aceptación: 13 de noviembre de 2015

\footnotetext{
Artículo de reflexión como resultado del proyecto de investigación titulado: "La auditoría forense un mecanismo para detectar el fraude en los estados financieros en empresas del sector privado en Colombia".

2 Contadora pública de la Fundación del Área Andina, estudiante de especialización en Revisoría Fiscal y Auditoria Forense.yzambrano@areandina.edu.co
} 


\title{
Resumen
}

El papel de la auditoría forense, como mecanismo para detectar el fraude, ha cobrado cada vez más importancia en la obtención de pruebas que son utilizadas por los tribunales para impartir justicia. El contador forense es un profesional que hoy goza de buen prestigio, la sociedad encuentra en él un aliado contra la corrupción, pues previene, investiga, detecta y evalúa irregularidades ocurridas al interior de las organizaciones tanto públicas como privadas. En el desarrollo de presente trabajo se determinó la importancia de la auditoria forense como mecanismo efectivo en la detección de los fraudes financieros en Colombia, se identificaron las aplicaciones de esta labor en la obtención de pruebas útiles para impartir justicia, igualmente se verificaron las practicas más utilizadas por los perpetradores de este ilícito, aportando fundamentos en el conocimiento del auditor. Se revisa la normatividad aplicada para castigar los delitos por fraude en estados financieros, con el fin de sentar un precedente en la responsabilidad del contador público con la sociedad; por último, se muestran los casos representativos en los que este tipo de delito afecto seriamente el país y las sanciones impuesta a los defraudadores.

Palabras clave: auditoria forense, corrupción, detección, prevención, mitigar, fraude, defraudador.

\section{Forensic audit: An effective mechanism to detect fraud in Colombian financial statement}

\begin{abstract}
The role of forensic audit as a mechanism to detect fraud, has become increasingly important in the obtaining of evidence that are used by the courts to dispense justice. The forensic accountant, is a professional that today enjoys good prestige, society finds in him/her as an ally against corruption, because he/she prevents, investigates, detects and evaluates irregularities occurring within public and private organizations. In the develop of this work, it was determined the importance of forensic accounting as an effective mechanism in the detection of financial fraud in Colombia. Moreover, there were identified the applications of this work in obtaining useful evidence to
\end{abstract}


dispense justice. Also, there were verified the most used practices by the perpetrators of this crime, bringing fundamentals in the auditor's knowledge; bringing fundamentals in the auditor's knowledge. It is analyzed the regulations applied to punish crimes of fraud in financial statements, in order to set a precedent for the responsibility of the public accountant with society. Finally, it is shown the representative cases in which this crime affected the country and the sanctions imposed on fraudsters.

Key words: audit forensics, corruption, detection, prevention, mitigation, fraud, the fraudster.

\section{A auditoria forense: um mecanismo efetivo para detectar a fraude de estados financeiros em Colômbia}

\section{Resumo}

O papel da auditoria forense como mecanismo efetivo para detectar a fraude, tem colaborado cada vez mais importância na obtenção de provas que são utilizadas pelos tribunais para fazer justiça. $\mathrm{O}$ auditor é um profissional respaldado pela sociedade, que encontra nele um aliado contra a corrupção, pois ajuda na prevenção de fraude, vai muito além da investigação tradicional, detecta e avalia irregularidades ocorridas ao interior das organizações tanto públicas como privadas. No desenvolvimento do presente trabalho determinou-se a importância da auditoria forense como mecanismo efetivo na detecção dos fraudes financeiros em Colômbia, se identificaram as aplicações deste labor na obtenção de provas úteis para se ter justiça, igualmente verificaram-se as práticas mais utilizadas pelos perpetradores deste ilícito, colaborando com os fundamentos no conhecimento do auditor; é revisada a normatividade aplicada para castigar os delitos por fraude em estados financeiros, por último é mostrado alguns casos ocorridos em país nos quais este tipo de delito afeta seriamente a economia nacional, além das sanções impostas aos defraudadores.

Palavras chave: auditoria forense, corrupção, detecção, prevenção, fraude, defraudador. 


\section{Introducción}

A través de los años, han surgido varios tipos de auditoría cada una en búsqueda de la detección de errores que puedan causar desviaciones de recursos o que evidencien deficiencias dentro de la administración tanto de las organizaciones como del Estado mismo. Todas han sido creadas con fines específicos y con el firme propósito de mitigar errores, analizar de manera razonable la situación financiera y los resultados obtenidos en la operación, con el objetivo de hacer una mejor toma de decisiones.

El Banco de la República (2012), expresa que son innumerables y muy creativas las formas en que pueden concebirse en la actualidad los fraudes en estados financieros. Habitualmente, manejan varias entradas en el libro diario en las que se involucran diferentes tipos de falsedades, convirtiéndose en el delito más difícil de detectar. La auditoría forense en este sentido ha presentado una gran evolución adaptándose a las exigencias del medio que cada vez presenta más sofisticación en este tipo de hechos.

El fraude a los estados financieros es uno de los más utilizados no sólo en Colombia sino en todo el mundo, que consiste en la inclusión de información distorsionada dentro de los estados financieros, donde generalmente se sobreestiman activos o ingresos o se subestiman pasivos o gastos. Los estados financieros de una organización pueden ser tal vez una mirada a los asuntos financieros ante inversionistas, entidades bancarias, entes de control, aseguradoras y todo su entorno comercial; todas las presiones ejercidas por el medio con el fin de mostrar resultados, hacen que se generen estados financieros fraudulentos.

Este tipo de delito es perpetrado generalmente por los gerentes y directores de las compañías con la intención de afianzar la imagen económica y el prestigio de las mismas. Es evidente que la gerencia puede beneficiarse directamente del fraude cuando venden acciones, reciben bonos de desempeño o al utilizar el reporte falso para ocultar otro fraude.

\section{Planteamiento del problema}

Según Rozas (2009), los delitos económicos han mostrado un incremento lamentable en los últimos años. Esto los podemos evidenciar al escuchar, ver y leer las noticias de nuestro país en las que cotidianamente nos informan sobre los crímenes económicos cometidos a lo largo y ancho, y que salpican todas las esferas de la sociedad.

Se puede leer sobre magistrados de las altas cortes que aprovechan su posición para manipular decisiones judiciales, militares involucrados en redes de desfalco a la salud, 
a reconocidos empresarios acusados por delitos de captación masiva, estafa, administración desleal, ocultamiento, alteración o destrucción de material probatorio, concierto para delinquir, en fin son tantos los fraudes que nos aquejan y que comprometen la imagen del país ante el mundo (Miranda, 1970).

El estudio realizado por KPMG (2011), asegura que la imagen positiva que reflejen las empresas ante clientes, proveedores, inversionistas, entes de control y socios estratégicos será fundamental para el logro de los objetivos propuestos. En este sentido, su adversario principal es el riesgo de convertirse en víctimas de fraudes, que quebranten el patrimonio así como su imagen corporativa. Son significativos los niveles de incidencia de fraudes evidenciados en este estudio, principalmente atribuidos a la Alta Dirección, el resultado muestra las graves dimensiones de lo que está sucediendo en las organizaciones colombianas, por lo que se hace necesario extremar las medidas de control y Gobierno Corporativo.

Los resultados obtenidos en el estudio de KPMG (2013), analizaron las repercusiones originadas por los fraudes en las empresas colombianas, determinando que casi 7 de cada 10 empresas que operan en el país han padecido cuando menos un fraude en los últimos doce meses, causando unos costos estimados por crímenes económicos de $\$$ 3.600 millones de dólares que representan el 1\% del PIB nacional, donde el 51\% del daño económico fue causado por el fraude financiero.

La responsabilidad del auditor es bien importante pues según la NIA $240^{3}$ (Instituto de Contabilidad de Cuentas, 2013) expresa: "consecuentemente, el auditor busca suficiente evidencia apropiada de auditoría de que no han ocurrido fraude y error que puedan ser de importancia para los estados financieros o que, si han ocurrido, el efecto del fraude está reflejado en forma correcta en los estados financieros o que el error está corregido. La probabilidad de detectar errores ordinariamente es más alta que la de detectar fraude, ya que el fraude ordinariamente se acompaña por actos específicamente planeados para ocultar su existencia."

En el caso tan controvertido de Interbolsa evidenciado el 19 de mayo de 2013, según lo revela el superintendente financiero, en una investigación posterior fue hallada toda clase de argucias para maquillar los balances. Los pasivos por ejemplo eran registrados como abonos de crédito o simplemente se llevaban a fondos al exterior sin ninguna clase de aval. Es así que se esclarecen dudas sobre los manejos turbios de la organización, sin eximir de sus responsabilidades a la Superintendencia. (Sarmiento, 2013).

$3 \quad$ Norma Internacional de Auditoria 240. Responsabilidades del Auditor en la Auditoria de Estados Financieros con Respecto al Fraude. 
Para Rozas (2009), ante el constante crecimiento del fraude y la corrupción, la demanda de investigadores y analistas del fraude se hace cada vez más grande. La respuesta inmediata y efectiva a este fenómeno ha contribuido al desarrollo de la auditoría forense o auditoría del fraude, que tiene como misión principal la asistencia a las organizaciones en la identificación de las áreas críticas de riesgo, además de desarrollar mecanismos para hacerles frente y sobreponerse a ellas. Adicionalmente se involucra en las investigaciones y en los procedimientos legales, con el fin de estudiar y entender la manera como los acreedores confía en los auditores cuando usan, especialmente, estados financieros prospectivos en situaciones de alto riesgo.

Al respecto Cano y Lugo (2005), señala a la auditoría forense como una herramienta efectiva en la investigación de los delitos financieros, así como un mecanismo fundamental en el control y prevención de estos, pues no necesariamente la Auditoría forense se concibió para detectar un hecho delictivo, también sirve para esclarecer la verdad de los acontecimientos y exonerar de responsabilidad a un sospechoso que sea inocente o a una empresa o entidad que haya sido acusada de un fraude con la intención de obtener beneficios económicos.

Por otra parte, el auditor forense no debe estar ajeno a comprender que ante la globalización se vienen firmando acuerdos bilaterales o entre bloques comerciales; esto aceleró la estandarización de normas y leyes no solo de tipo penal para proteger los negocios, sino comerciales y de información, estos hechos ponen en plena vigencia la homologación de las Normas Internacionales de Auditoría, las Normas Internacionales de Contabilidad y las Normas de Información Financiera, conocidas como las NIA's, NIC's y NIF's adicionalmente están en pleno vigor leyes extraterritoriales como "USA Patriot", "Victory Act" y "Sarbanes-Oxley".

El estudio de KPMG (2013), hace referencia a que todo ilícito por irrelevante que parezca, tiene efectos secundarios en el tejido social de la compañía que afecta y, en consecuencia, vulnera también las reglas sociales que hacen posible que una industria o un sector determinado pueda prosperar. Dejando como consecuencia una estela de desempleo y falta de oportunidades para seguir innovando.

Igualmente KPMG (2013), sugiere que para mitigar el riesgo de ser víctima de un fraude, la organización requiere de un sistema de actividades y controles que en su conjunto, reduzcan al mínimo posible la probabilidad de ocurrencia de fraude y

\footnotetext{
Ley Sarbanes-Oxley: En el mes de julio de 2002, el presidente de los Estados Unidos la promulgo. Incluye cambios profundos en las reglamentaciones federales sobre valores, que podrían representar la reforma más significativa desde la sanción de la Securities Exchange Act. de 1934.
} 
conductas impropias, y que al mismo tiempo maximicen la posibilidad de detectarlas, antes de que signifiquen un quebranto económico significativo. Una estrategia de administración de riesgos de fraude que sea efectiva y orientada a la empresa abarcará actividades, mecanismos y controles que tengan tres objetivos: prevención, detección y respuesta.

\subsection{Formulación del problema}

¿Es la Auditoria Forense un mecanismo para detectar los fraudes en los Estados Financieros en Colombia?

\subsection{Sistematización del problema}

a. ¿Cuáles son las prácticas más utilizadas en el fraude a los Estados financieros en Colombia?

b. ¿Qué normatividad aplica para detectar y castigar este tipo de delito?

c. ¿Cuáles son los casos más sonados en Colombia y qué tipo de sanciones se le ha impuesto a sus perpetradores?

\section{Objetivos}

\subsection{General}

Determinar si la auditoría forense es un mecanismo efectivo en la detección de los fraudes financieros en Colombia.

\subsection{Específicos}

- Indagar sobre las prácticas más utilizadas para cometer Fraudes de Estados Financieros en Colombia.

- Identificar la normatividad aplicada en Colombia para detectar y castigar los delitos por fraude en Estados financieros en Colombia.

- Verificar los casos más sonados en Colombia y las sanciones impuestas según la regulación colombiana.

\section{Justificación}

Según Rozas (2009), la globalización de la economía con una vertiginosa evolución, hace que se produzcan situaciones de conflicto originadas por múltiples motivos, esto sin duda afecta ostensiblemente a distintas áreas de operación en las compañías. Las 
consecuencias pueden ocasionar incrementos importantes en los costos de la organización, afectación en sus operaciones internas, consecuencias negativas en la imagen proyectada al mercado o incluso serias repercusiones en su equilibrio patrimonial.

El fraude en los estados financieros se hace una de las preocupaciones más representativas del ambiente de los negocios en la actualidad del país, por lo que combatirlo se ha convertido en uno de los mayores objetivos corporativos tanto en el sector privado como en el público, es por ello que surge la denominada: Auditoría forense como un mecanismo en la lucha contra este flagelo.

\section{Antecedentes}

De acuerdo con Leal (2010), "el fraude en los estados financieros consiste en la falsificación o alteración deliberada de la situación financiera de una organización a través de adiciones u omisiones intencionales a las transacciones o cifras que los componen, con el propósito de engañar a los usuarios de la información. Este tipo de fraude se utiliza para ocultar problemas del negocio que han impedido la obtención del nivel de rentabilidad esperado o el logro de indicadores requeridos, induciendo a que las partes interesadas tomen decisiones basadas en información no ajustada a la realidad de la empresa. Se presenta en operaciones como: compra de acciones, aportes de capital, otorgamiento de créditos, suministro de materias primas o servicios, adquisición, fusión o venta de empresas".

Entre los motivos más representativos se puede decir que se comete para obtener o renovar cupos de endeudamiento con las entidades financieras y bancos, para elevar el precio de las empresas o sus acciones, para potenciar su prestigio dentro del sector y para obtener beneficios tributarios.

Es indiscutible que los delitos económicos continuarán lesionando a las empresas en Colombia por las múltiples tipicidades con los que se cometen, por la amplia gama de defraudadores, la variedad de recursos que poseen y el alto grado de sofisticación que utilizan. Es evidente que no existe en la actualidad una solución universal para esta problemática, pero la mejor forma de hacerle frente y detenerlo es compartir experiencias $\mathrm{y}$ conocimientos que permitan fortalecer el control en las organizaciones.

La auditoría forense investigativa está orientada a identificar la existencia de fraudes mediante una profunda investigación llegando a establecer entre otros aspectos, los siguientes: determinar la cuantía del fraude, efectos directos e indirectos, posible 
tipificación, presuntos autores, cómplices y encubridores (Fontán, 2009). La Auditoría forense se considera mucho más efectiva que la auditoría de los estados financieros en la investigación del fraude contable (Estupiñan, 2006). El fraude contable al ocultar activos, pasivos, ingresos o sobreestimar costos en estados financieros, busca defraudar al Estado, a los accionistas, a los acreedores, pues se logra con ello pagar menos impuestos, distribuir menos dividendos, constituir menores reservas que protejan el patrimonio y las deudas a favor de los acreedores (Bermúdez, 2000).

La auditoria forense hace cada día más valiosa la labor del auditor: hace un diagnóstico, previene y estudia los hechos de corrupción en las organizaciones. La mayor parte de los resultados del Auditor van a conocimiento de los jueces (especialmente penales), para impartir justicia. El objetivo esencial de la Auditoria Forense se orienta a la investigación de hechos dolosos en el nivel financiero originados en las empresas privadas, oficiales o en cualquier ente que maneje recursos (Maldonado, 2003, p. 9.)

El fraude de estados financieros en Colombia es sin duda una de las problemáticas que causa más efectos nocivos al interior de las empresas en las que se comete el ilícito, produciendo serias repercusiones sobre accionistas, clientes, proveedores, sector financiero, entes de control y economía en general que dependen de dicha información para la toma de decisiones acertadas; también lastima en alto grado la fe pública de contadores, revisores fiscales y auditores que día a día pierden credibilidad al prestarse o tolerar este tipo de prácticas en los altos ejecutivos, empresarios, administradores o propietarios.

La auditoría forense surge como un mecanismo en la prevención, detección y defensa ante este tipo de fraude, así como un instrumento en la lucha contra la corrupción; es por ello que se busca a través de esta investigación determinar las prácticas más utilizadas para cometer este tipo de crimen económico, indagando los casos más controversiales de fraude financiero en Colombia y haciendo un seguimiento a las sanciones impuestas a sus perpetradores a través de la revisión de la normatividad colombiana.

En la investigación de los tipos de fraude a los estados financieros, se puede evidenciar que descubrir este tipo de ilícito adquiere un grado de dificultad cada vez mayor, ya que sus perpetradores diseñan técnicas más sofisticadas para hacerlo indetectable; es por ello que el auditor forense debe ser un profesional escéptico, analítico, curioso, creativo y discreto, capaz de identificar cualquier situación que lo alerte ante un caso de fraude y que le permita a través de su experiencia, entrenamiento, ética, pericia y amplio conocimiento obtener todo el material probatorio que determine si se encuentra ante un crimen económico. 


\section{Marco de referencia}

\subsection{Fundamentación teórica}

El fraude se encuentra definido como: cualquier acto ilegal caracterizado por engaño, ocultación o violación de confianza. Estos actos no requieren la aplicación de amenaza de violencia o de fuerza física. Los fraudes son perpetrados por individuos y por organizaciones para obtener dinero, bienes y servicios, para evitar pagos o pérdidas de servicios, o para asegurarse ventajas personales o de negocio.

La palabra "fraude" abarca un concepto jurídico bastante amplio, a los efectos de las NIA, al auditor le concierne el fraude que da lugar a incorrecciones materiales en los estados financieros. En la labor del auditor son relevantes dos tipos de inexactitudes intencionadas: las debidas a información financiera fraudulenta y las provocadas por una apropiación indebida de activos. Aunque el auditor puede tener indicios o, en casos excepcionales, identificar la existencia de fraude, el auditor no determina si se ha producido efectivamente un fraude desde un punto de vista legal ${ }^{5}$ (Ref: Apartado A1-A6).

\subsection{Antecedentes del problema}

Como lo menciona Rozas (2009), el dinamismo presente en la actividad empresarial, hace que la Auditoría forense se especialice, en esfuerzos por detectar y prevenir el fraude en los estados financieros. Con el paso del tiempo ha ido ampliando su campo de acción en la medida que ha tecnificado procedimientos específicos para su lucha contra el crimen financiero y trabaja de la mano con los tribunales de justicia. La Auditoría forense, se fundamenta en el escepticismo del auditor, partiendo de la base que todas las empresas son susceptibles de padecer algún tipo de fraude, es por ello que se requiere implementar y aplicar un conjunto completamente novedoso de técnicas para la detección y análisis de este crimen económico. El valor de la prueba (en general), así como el de la evidencia (de auditoría) adquieren un significado de reales dimensiones cuando pueda ser aceptado como material probatorio útil ante los estrados judiciales.

La Auditoria Forense en la detección del fraude en estados financieros se hace cada vez más importante ya que según lo expresado por Leal (2010). La ciencia contable cuenta con un nuevo reto: participar activamente en la prevención de los crímenes económicos y específicamente en la detección del fraude corporativo. Así como surgen rápidamente las formas de hacer negocios, también lo hacen las formas de defraudación,

La Norma Internacional de Auditoría (NIA) 240. Características del fraude. 
razón por la cual los profesionales que intervienen en la prevención del delito deben contar con herramientas suficientes que brinden ayuda en la detección y cuantificación del impacto causado por el fraude financiero, para mejorar la confianza a los usuarios de la información financiera.

Según definición de Bernate (2007), la contabilidad creativa hace referencia a todas aquellas prácticas útiles para la empresa en la transformación indebida de la información financiera y que se encuentran motivadas generalmente en disminuciones no esperadas en las ventas por cambios negativos en la participación del mercado, por presiones en la elaboración de presupuestos que no corresponden a la realidad, así como las financieras ocasionadas por programas de incentivos que dependen del comportamiento financiero de la empresa en el corto plazo.

Para Leal (2010), las innumerables clases de evidencia obtenidas y presentadas por el Auditor forense pueden ser consideradas como pruebas analíticas, documentales, físicas y testimoniales acondicionadas a los requerimientos de su labor. Para lograr el objetivo que se espera, éste profesional debe realizar una planeación estratégica en la que incluya criterios de selección enfocados en las técnicas de auditoria que le brinden la fundamentación necesaria en la ejecución y desarrollo de su trabajo.

Según Badillo (2013), para las compañías el porcentaje de las pérdidas por fraude es directamente proporcional a la jerarquía que poseen sus perpetradores; por tal razón, se establece una relación inversa entre el porcentaje de personal en un determinado nivel organizacional y el porcentaje de pérdidas por fraude que provoca.

Grafica 1. Porcentaje de participación de los perpetradores en fraudes financieros.

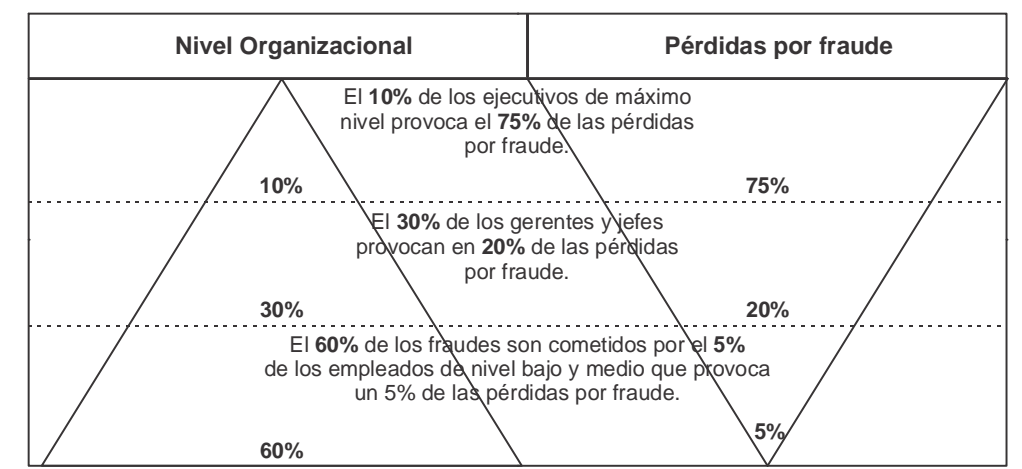

Fuente: Baudilio Jorge (2013), Association of Certified Fraud Examiners - ACFE.6

$\overline{6} \quad$ Association of Certified Fraud Examiners - ACFE; www.CFEnet.com 


\section{Metodología}

\subsection{Tipo de investigación}

La investigación es descriptiva ya que se analizó de manera sistemática las características del fraude en estados financieros en Colombia, identificando sus principales tipologías y la normatividad que rige para este tipo de delitos. El presente estudio buscó solamente describir una problemática pero sin la comprobación de hipótesis, teorías o predicciones.

\subsection{Diseño de la investigación}

Con el fin de responder al interrogante surgido en la presente investigación se utiliza un diseño de naturaleza flexible, que se construya con los puntos de vista de varios autores que estudiaron el fraude en estados financieros. Se optó por un enfoque interpretativo dentro de un análisis cualitativo, haciendo uso de información documental obtenida en artículos, libros, revistas, que ampliará el conocimiento del tema tratado.

Dentro de la normatividad existente para este tipo de delito económico se revisaron los elementos éticos de la profesión contable y las implicaciones negativas que se producen cuando no son aplicados.

\subsection{Resultados}

La constante búsqueda del ser humano por satisfacer las necesidades de su entorno ha incentivado el nacimiento de múltiples formas de hacer negocios, de estas iniciativas surgen nuevas compañías y con ellas también las circunstancias de riesgo, el avance constantes de la tecnología hacen que el auditor tenga que adquirir un perfil especializado; para perfeccionar su formación debe -adicional a los conocimientos de contabilidad, finanzas, tecnología y auditoría habituales- incluir aspectos de investigación legal, ciencias forenses y formación jurídica, con énfasis en la recolección de pruebas y evidencias, peritaje, así como obtener la alta calificación técnica de análisis y revisar los procesos de riesgo y control; incluyendo todos los principios y valores que finalmente lo conduzcan a la detección de irregularidades (Mantilla, 2003).

Para asumir el compromiso de una auditoría forense, el profesional debe enfatizar en el desarrollo de competencias y enfocar el trabajo hacia agregar valor a la institución, con aspectos diferenciadores que les garanticen: 
1) Alinear y armonizar lo prospectivo de las auditorías estratégicas con lo reactivo de la Auditoría Forense, dado que esta inicia con ciertas evidencias de hechos criminales y no sobre aspectos de prevención.

2) Desarrollar y aplicar técnicas específicas para la oportuna detección y análisis de delitos de corrupción y aquellos trabajos relacionados con la aplicación de la justicia.

3) Asistir a las compañías en la identificación de las áreas críticas o vulnerables y sugerir el desarrollo de sistemas y procedimientos con la intención de prevenir y manejar los riesgos de fraude en esas áreas.

Según Leal (2010), se podría considerar que las herramientas que proporciona la Auditoría Forense hacen parte de un conjunto de procedimientos y técnicas que, aplicados de forma integrada y secuencial, permiten hallar pruebas y evidencias suficientes, competentes, relevantes y útiles que concluyan el trabajo de investigación, testimonios y elementos probatorios ante estamentos de control y vigilancia, judiciales, regulatorios o de la empresa que requirió de sus servicios. 
Grafica 2. Tipologías más utilizadas en el fraude a los estados financieros.

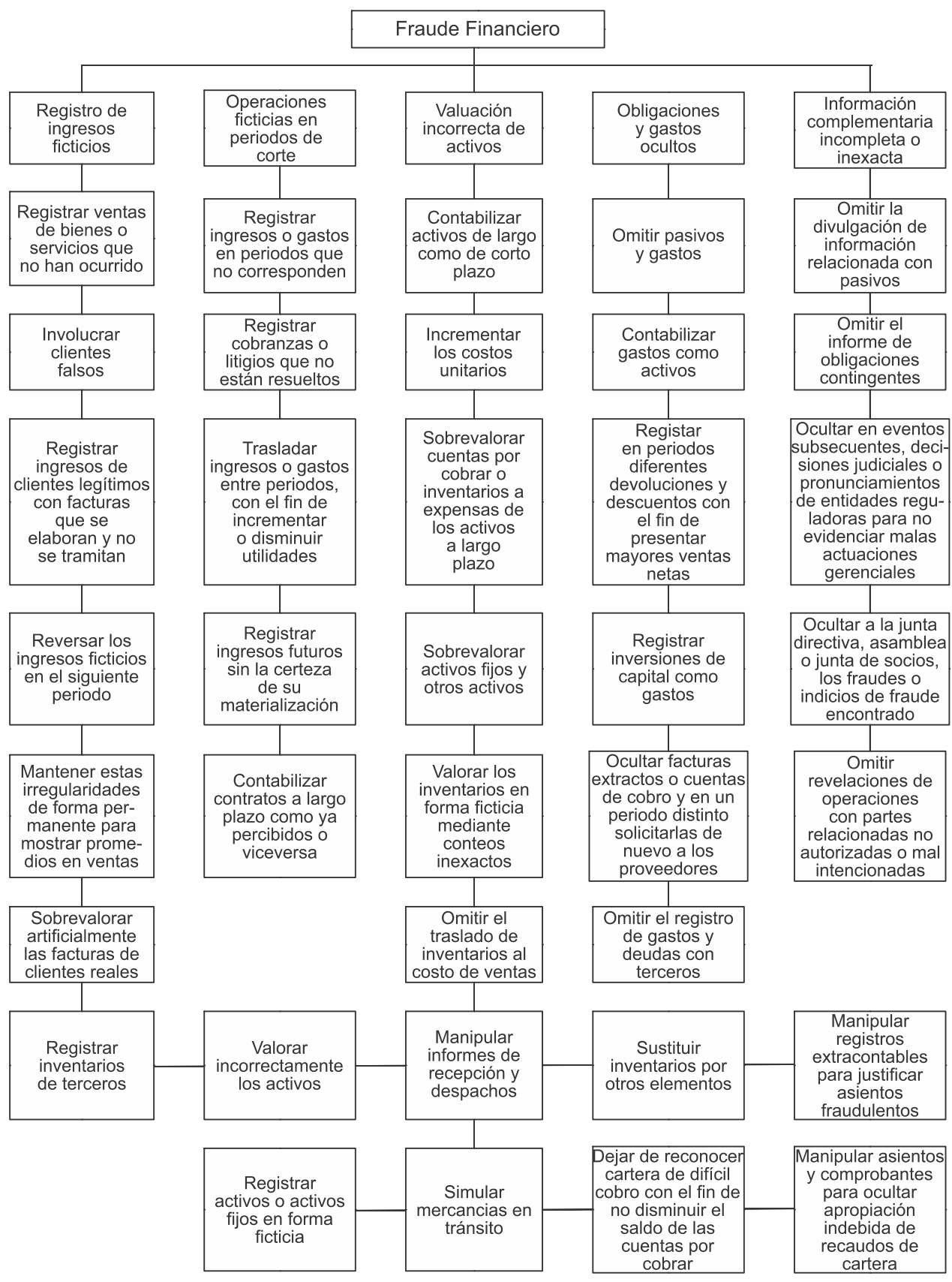

Fuente: elaboración propia a partir de Leal (2010) 
De acuerdo con el estudio realizado por KPMG (2013), algunas de las prácticas más utilizadas en las empresas colombianas para llevar a cabo los fraudes en los estados financieros son:

- Registro de ingresos ficticios para sobredimensionar el comportamiento real de la compañía y de esta manera tener, por ejemplo, una mejor posición a la hora de negociar una posible venta de la compañía.

- Registrar como venta un desplazamiento de mercancía de un almacén a otro o no registrar devoluciones de inventario, de tal forma que se mantengan un nivel de ventas alto y con ello obtener bonos asociados a "productividad" de los altos ejecutivos.

- Reconocer como ingresos presentes perspectivas de ingresos futuros (por ejemplo aquellos derivados de contratos a largo plazo o beneficios obtenidos de instrumentos financieros), para reflejar una liquidez a corto plazo que asegure un préstamo bancario más generoso.

- Registrar como un gasto futuro un pasivo presente de tal forma que las cuentas de resultados muestren mayores rendimientos y también menores pasivos, de esta manera alterar los ratios de las razones financieras presentadas a los accionistas de la empresa.

- Registrar la depreciación de un activo en un plazo de tiempo mayor a la de su vida útil estimada, de tal forma que el valor de los activos mostrados en libros no corresponden con la realidad.

- Registrar de manera imprecisa o incluso no registrar una contingencia derivada, por ejemplo, de un litigio legal que se estima se va a perder y, no obstante, no reconocerla para afectar los deberes de hacer y no hacer ("convenants") con los bancos acreedores.

- Registrar como arrendamiento puro cierta maquinaria en lugar de arrendamiento financiero, para reducir así la deuda en estados financieros y reflejar una mejor posición financiera.

\subsection{Fundamentación legal}

De acuerdo con Sadder (2013), se puede asegurar que en la actualidad no se cuenta con un cuerpo definido de principios y normas que regulen la Auditoría Forense, sin embargo, teniendo en cuenta que este tipo de auditoría en términos contables posee un campo mucho más amplio de acción que la auditoría financiera, por su amplitud debe sustentarse en los postulados de las normas de auditoría generalmente aceptadas y de manera especial en las referidas al control, prevención, detección y divulgación de fraudes, tales como las normas de auditoría SAS Nº 82 y N 99 y la Ley SarbanesOxley. 
SAS N'82 "Consideraciones sobre el Fraude en una Auditoría de Estados Financieros": Esta norma entró en vigencia a partir de 1997 ofrece orientación sobre las responsabilidades del auditor por detectar y reportar explícitamente el fraude y efectuar una valoración del mismo. Al evaluar el fraude administrativo se debe considerar 25 factores de riesgo que se agrupan en tres categorías:

- Características de la administración e influencia sobre el ambiente de control (seis factores);

- Condiciones de la industria (cuatro factores); y

- Características de operación y de estabilidad financiera (quince factores).

De manera especial se debe resaltar como la SAS $\mathrm{N}^{\circ} 82$ señala que el fraude frecuentemente implica: (a) una presión o incentivo para cometerlo; y (b) una oportunidad percibida de hacerlo.

Respecto del fraude, el denominado "Triángulo del Fraude" es uno de los conceptos fundamentales de la Declaración sobre Normas de Auditoría DNA (SAS) 99, mismo que constituye una ayuda para que el auditor entienda y evalúe los riesgos de fraude en la organización. El fraude corporativo en esta Norma es denominado: "reportes financieros fraudulentos", otros autores lo denominan "revelaciones financieras engañosas", "fraude de la administración", "crimen corporativo" o "crimen de cuello blanco".

La SAS 99. Consideración del Fraude en un Resumen de la Intervención del Estado Financiero, reemplaza al estándar anterior del fraude SAS 82, el cual es eficaz para los estados financieros que se presenten a partir de diciembre 15 de 2002 y trata en su contenido la descripción y características del fraude, la importancia de ejercitar escepticismo profesional, obtención de la información necesaria para identificar los riesgos de la declaración errónea debido al fraude, evidencia y documentación de la intervención, comunicación sobre el fraude a la gerencia y uno de los cambios más grandes está en el área de desarrollar respuestas apropiados a los riesgos identificados. 
Grafica 2. Triángulo del Fraude

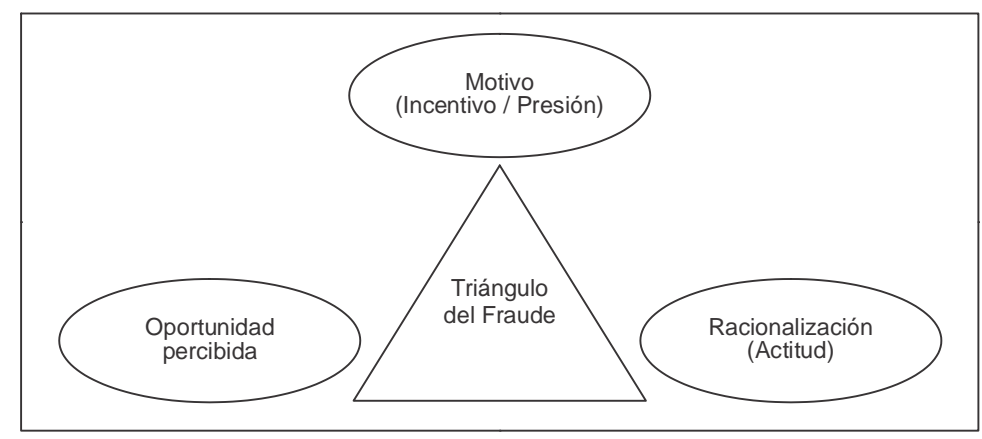

Fuente: DNA (SAS) 99 - Triángulo del Fraude. ${ }^{7}$

El fraude frecuentemente involucra de manera simultánea los tres elementos antes señalados:

- Motivo.- Presión o incentivo (necesidad, justificación, desafío) para cometer el fraude (la causa o razón). Ejemplos de motivos para cometer fraude pueden ser: alcanzar metas de desempeño (como volúmenes de venta), obtener bonos en función de resultados (incremento en las utilidades o rebaja en los costos) y mantener el puesto demostrando ficticios buenos resultados, deudas personales.

- Oportunidad percibida.- El o los perpetradores del fraude perciben que existe un entorno favorable para cometer los actos irregulares pretendidos. La oportunidad para cometer fraude se presenta cuando alguien tiene el acceso, conocimiento y tiempo para realizar sus irregulares acciones. Las debilidades del control interno o la posibilidad de ponerse de acuerdo con otros directivos o empleados para cometer fraude (colusión) son ejemplos de oportunidades para comportamientos irregulares (Martínez, 2015).

- Racionalización.- Es la actitud equivocada de quien comete o planea cometer un fraude tratando de convencerse a sí mismo (y a los demás si es descubierto), consciente o inconscientemente, de que existen razones válidas que justifican su comportamiento impropio; es decir, tratar de justificar el fraude cometido. Ejemplos de racionalización para justificar el fraude cometido pueden ser: alegar baja remuneración (convencerse de que no es fraude sino una compensación salarial, un préstamo), falta de reconocimiento en la organización (convencerse de que es una bonificación), fraude

$7 \quad$ Declaración sobre Normas de Auditoria DNA (SAS)-99. "La Consideración del fraude en los Estados Financieros". 
cometido por otros empleados y/o directivos (convencerse de que si otros cometen fraudes el fraude propio está justificado).

La NIA 240 contiene las "Responsabilidades del Auditor en la Auditoría de Estados Financieros con respecto al fraude". Trata de las responsabilidades que tiene el auditor con respecto al fraude en la auditoría de estados financieros. Además, asegura que "los responsables del gobierno de la entidad y la dirección son los principales responsables de la prevención y detección del fraude.

La NIA 250 esta norma internacional expone la responsabilidad del auditor de tener en cuenta y asumir las leyes y regulaciones relevantes en una auditoría de estados financieros. Estas leyes y regulaciones dependen de la entidad, determinando así su marco de referencia legal y regulador, que puede estar relacionado con el manejo de la entidad y los estados financieros. El incumplimiento de las leyes y regulación puede llevar a multas, sanciones o litigios que pueden afectar directamente los estados financieros.

De acuerdo con el Decreto 2649 de 1993, en referencia a las cualidades que se habían definido para la información contable. Artículo 4. Cualidades de la información contable. Para poder satisfacer adecuadamente sus objetivos, la información contable debe ser comprensible y útil. En ciertos casos se requiere, además, que la información sea comparable.

Con la entrada en vigencia de la Ley 1314 de 2009 se adicionó como cualidad la transparencia, introducida por el artículo 1, así: "Los estados financieros, brinden información financiera comprensible, transparente y comparable, pertinente y confiable, útil para la toma de decisiones económicas por parte del Estado, los propietarios, funcionarios y empleados de las empresas, los inversionistas actuales o potenciales y otras partes interesadas, para mejorar la productividad, la competitividad y el desarrollo armónico de la actividad empresarial de las personas naturales y jurídicas, nacionales o extranjeras".

Normas Internacionales de Información Financiera (NIIF) y Auditoría (NIA), por lo altos estándares de calidad que manejan para la revelación de información financiera y porque aseguran que la información se encuentre optimizada en aspectos como el control interno, las políticas contables, la difusión de sus estados financieros y las prácticas de gobierno corporativo para salvaguardar la transparencia (Baracaldo, 2013).

Con el decreto 2373 de 1956 se busca que los actos a cargo del Revisor Fiscal se ajustan a los requisitos legales y a los estatutos si es una persona jurídica, en los 
balances indica que han sido tomados fielmente de los libros, se ajustan a las normas legales y las cifras registradas en ellos reflejan en forma fidedigna la situación financiera a la fecha del balance, este articulo tuvo vigencia hasta la expedición de la ley 145 de 1960. (...)

La Ley 43 de 1990 señala en sus artículos 6 - Principios de contabilidad generalmente aceptados, 8 - Normas que deben observar los Contadores Públicos, 35 al 40 - Código de Ética Profesional (principios que constituyen las bases para el desarrollo del código de ética de la profesión del Contador Público, como son: integridad, objetividad, independencia, responsabilidad, confidencialidad, observaciones de las disposiciones normativas, competencia y actualización profesional, difusión y colaboración, respeto entre colegas y conducta ética).

Artículo 659 E.T. Sanción por violar las normas que rigen la profesión. Los Contadores Públicos, Auditores o Revisores Fiscales que lleven o aconsejen llevar contabilidades, elaboren estados financieros o expidan certificaciones que no reflejen la realidad económica de acuerdo con los principios de contabilidad generalmente aceptados, que no coincidan con los asientos registrados en los libros, o emitan dictámenes u opiniones sin sujeción a las normas de auditoría generalmente aceptadas, que sirvan de base para la elaboración de declaraciones tributarias, o para soportar actuaciones ante la Administración Tributaria, incurrirán en los términos de la Ley 43 de 1990, en las sanciones de multa, suspensión o cancelación de su inscripción profesional de acuerdo con la gravedad de la falta.

Artículo 660 E.T. Suspensión de la facultad de firma declaraciones tributarias y certificar pruebas con destino a la administración tributaria. Cuando en la providencia que agote la vía gubernativa, se determine un mayor valor a pagar por impuesto o un menor saldo a favor, en una cuantía superior a (590 UVT) originado en la inexactitud de datos contables consignados en la declaración tributaria, se suspenderá la facultad al contador, auditor o revisor fiscal, que haya firmado la declaración, certificados o pruebas, según el caso, para firmar declaraciones tributarias y certificar los estados financieros y demás pruebas con destino a la Administración Tributaria, hasta por un año la primera vez; hasta por dos años la segunda vez y definitivamente en la tercera oportunidad.

\section{Casos más controversiales en Colombia y que involucran fraude en los estados financieros}

En la tabla 1, se muestran los casos más sonados de fraude en estados financieros en Colombia. 


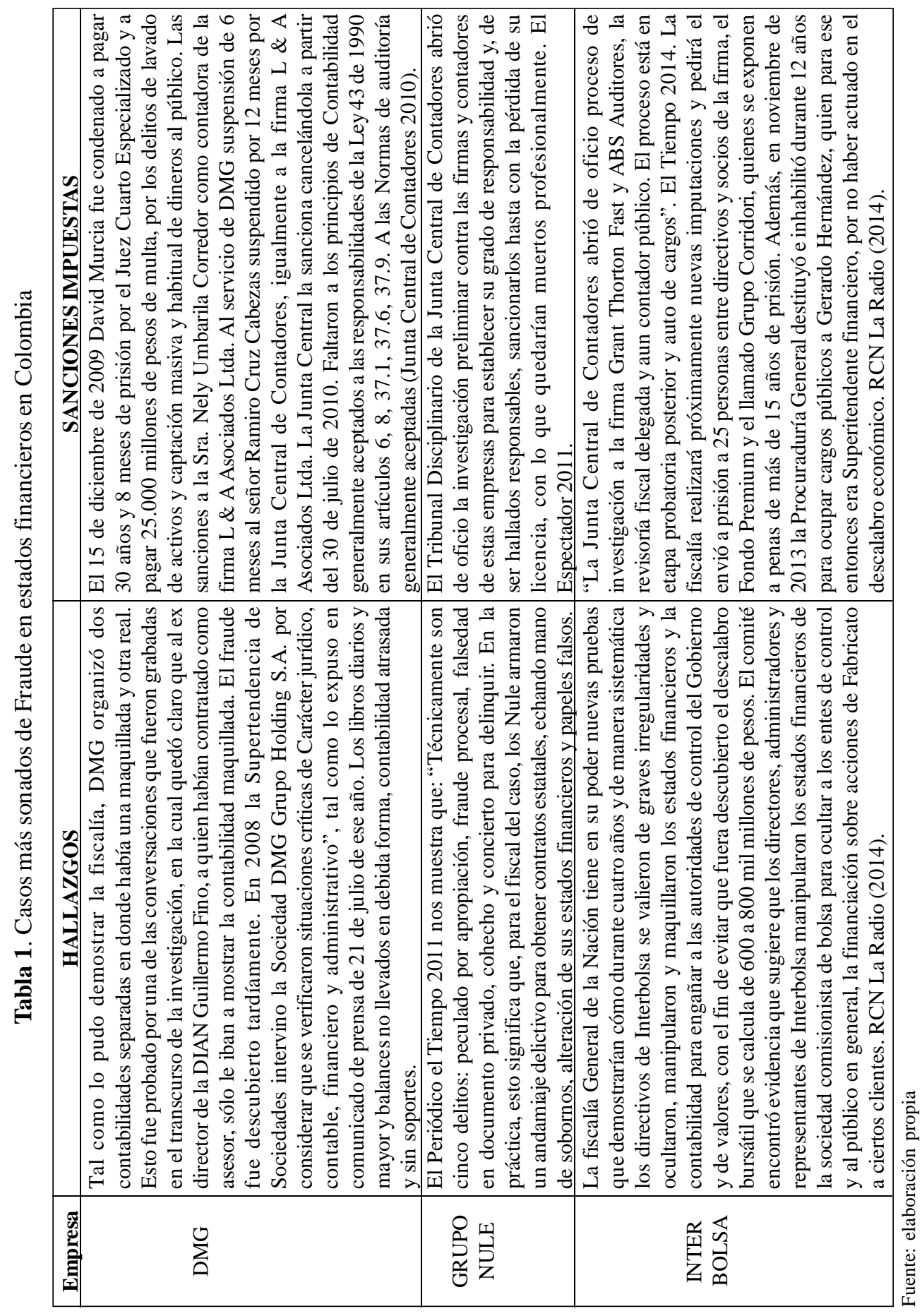




\section{Conclusiones}

Con la presente investigación se hace evidente el papel tan importante que debe jugar la Auditoría Forense en el buen actuar de las empresas en Colombia, no sólo en la detección de los crímenes económicos sino en la prevención de los mismos. El fraude en estados financieros es un crimen de cuello blanco cometido por los funcionarios de más alto rango y donde están involucrados contadores, revisores y auditores quienes son los que elaboran, certifican, firman o dictaminan los mismos.

Los entes de control y la Junta Central de Contadores deben establecer una regulación drástica en materia de sanciones, con el fin que sean castigados los crímenes económicos, igualmente a sus perpetradores se les debe aplicar todo el peso de la Ley, el compromiso de las empresas es el de extremar los controles y realizar un seguimiento constante a todos aquellos riesgos que se puedan presentar dentro de la empresa con el objetivo de disminuir su probabilidad de ocurrencia.

En la indagación sobre las sanciones impuestas a contadores, auditores y revisores fiscales involucrados en los grandes escándalos de fraude en estados financieros en Colombia se pudo comprobar que los castigos no guardan proporcionalidad con los crímenes cometidos y la defraudación al Estado, además de acuerdo con lo revisado no se evidencia sanciones ejemplarizantes a estos profesionales o simplemente aún estos hechos son materia de investigación por parte de la fiscalía y de la Junta Central de Contadores.

\section{Recomendaciones}

Como el adagio popular «el ejemplo empieza por casa», cada uno desde nuestro hogar así como desde las mismas universidades debe cultivar la ética y los valores morales en los futuros profesionales, más aún en la labor contable donde estamos obligados a dar fe pública sobre los hechos plasmados en los estados financieros. La educación debe brindar a las nuevas generaciones, bases fundadas en la honestidad, moralidad, ética y total rectitud; también es imprescindible que se trabaje sobre estos principios en las organizaciones, tratando de cerrar al máximo las brechas que propicien el fraude.

Para nuevas investigaciones sería importante realizar un seguimiento a los casos planteados, con el fin de establecer si los perpetradores de este tipo de fraudes responderán ante el Estado por el daño causado y con qué prontitud son resueltos este tipo de delitos por parte de la justicia colombiana. 
YANETH ZAMBRANO VARGAS

\section{Referencias Bibliográficas}

Association of certified fraud examiners (2015). Encuesta de fraude en Colombia 2013, (1), 1-37.

Badillo, J. (2013). Fraude financiero en las organizaciones. Recuperado de: http:// www.vhgconsulting.com/auditoria-forense-5/.

Banco de la República. (2012). Fraude en los estados financieros. Recuperado de: http://www.larepublica.co/empresas/fraude-en-los-estados-financieros_11124.

Baracaldo, N. (2013). ¿Es garante del principio de transparencia la implementación de las normas internacionales en Colombia? Cuadernos de Contabilidad, 14 (13). Recuperado de http://revistas.javeriana.edu.co/index.php/cuacont/article/ view/7914.

Bermúdez, J. M. (2000). Control, auditoría y revisoría fiscal. Bogotá: Ecoe Ediciones.

Bernate, F. (2007). Delitos de Falsedad en Estados Financieros. Bogotá: Editorial Universidad del Rosario.

Cano, M. y Lugo, D. (2005). Auditoria Forense en la investigación criminal del Lavado de Dinero y Activos. Bogotá: Ecoe Ediciones.

Colombia, Decreto 2649/1993, 29 de diciembre. Por el cual se reglamenta la contabilidad en general y se expiden los principios o normas de contabilidad generalmente aceptados en Colombia. Diario Oficial, 41.156.

Colombia, Decreto 2373/1956, 18 de septiembre. Por el cual se reglamenta la profesión de contador, y se dictan otras disposiciones. Diario Oficial, 29154.

Colombia, Ley 1314/2009, 13 de julio. Por la cual se regulan los principios y normas de contabilidad e información financiera y de aseguramiento de información aceptados en Colombia, se señalan las autoridades competentes, el procedimiento para su expedición y se determinan las entidades responsables de vigilar su cumplimiento. Diario Oficial, 47.409.

Colombia, Ley 43/1990, 13 de diciembre. Por la cual se adiciona la Ley 145 de 1960, reglamentaria de la profesión de contador público y se dictan otras disposiciones. 
Declaración sobre Normas de Auditoria DNA (SAS) - 99. (2002) La consideración del fraude en los Estados Financieros.

Estupiñan, R. (2006). Control interno y fraude con base en los ciclos transaccionales: análisis de informe COSO I y II. Bogotá: ECOE Ediciones.

Fontán, E. (2009). El impacto de la auditoría forense como técnica en la detección, prevención y control del fraude. Buenos Aires: Instituto de auditores forenses IDEAF.

González, F. (2014, mayo, 15). Contadores, en la mira por grandes escándalos del país. Periódico El Tiempo, recuperado de: http://www.eltiempo.com/economia/ indicadores/contadores-de-los-grandes-escandalos-del-pais/13994576

Instituto de Contabilidad de Cuentas. (2013). Norma Internacional de Auditoria 240: Responsabilidad del auditor en la auditoria de estados financieros con respecto al fraude. Popayán: Universidad del Cauca.

KPMG Advisory Services Ltda. (2011). Encuesta de Fraude en Colombia 2011. Recuperado de: http://www.kpmg.com/co/es/issuesandinsights/articles publications/paginas/encuestadefraudeencolombia2011.aspx

KPMG Advisory Services Ltda. (2013). Encuesta de Fraude en Colombia 2013. Recuperado de: http://www.kpmg.com/co/es/issuesandinsights/articles publications/paginas/encuestadefraudeencolombia2013.aspx

Leal, L. (2010). Desarrollo de técnicas y procedimientos aplicables al trabajo del Contador Público en el campo de la auditoria forense. Proyecto de Investigación. Gestión y Sociedad: Universidad de la Salle.

Mantilla, S.A. (2003). Auditoría 2005. Bogotá: Ecoe Ediciones.

Maldonado, M. (2003). Auditoría Forense: Prevención e Investigación de la Corrupción Financiera (1a. ed). Ecuador: Editora Luz de América.

Marín, A. (2011, Mayo, 20). Contadores de los Nule en la mira. El Espectador, recuperado de http://www.elespectador.com/noticias/judicial/contadores-delos-nule-mira-articulo-271539

Martínez, V. (2015, junio, 03). Buenas prácticas de auditoría y control interno en 
las organizaciones. Periódico Portafolio, recuperado de: http:// www.portafolio.co/opinion/blogs/buenas-practicas-de-auditoria-y-controlinterno-en-las-organizaciones

Miranda, R. (1970). Delitos contra el orden económico. Buenos Aires: Ediciones Pannedille.

RCN la Radio. (2014, mayo, 06). “Auditoría revela que interbolsa maquillaba estados financieros durante cuatro años, para ocultar delitos".

Rozas, A. (2009). Auditoria Forense. Revista de la Facultad de Ciencias Contables. 16 (32), 73-101.

Sadder, Y. (2013). Auditoria forense como herramienta para prevenir el fraude financiero. Tesis Pregrado. Universidad Militar Nueva Granada, Colombia.

Sarmiento, E. (2013, mayo). Las Argucias del Interbolsa. El Espectador, recuperado de: http://www.elespectador.com/opinion/argucias-de-interbolsa 